\title{
Muerte y religión: del Tolstoi maduro al joven Wittgenstein ${ }^{1}$
}

\section{Death and religion: from the old Tolstoy to the young Wittgenstein}

\author{
Nicolás SÁNCHEZ DURÁ \\ (Universidad de Valencia)
}

Recibido: 27/04/2011

Aceptado: 15/11/2011

\section{Resumen}

Mi propósito es doble. Mostrar cómo la pregunta por el sentido de la vida y la matriz del sentimiento religioso del Tolstoi maduro, que él considera cristianismo verdadero, se funda en la experiencia subjetiva del miedo ante la muerte y la angustia ante la soledad que la misma comporta. Este aspecto es el núcleo de su religiosidad por cuanto de él se deriva el valor de la fraternidad, centro de una moral humanista y altruista paradójica que sacraliza el vínculo amoroso entre los hombres a la par que se fundamenta en el sometimiento a la voluntad de Dios. Por otra parte, las concepciones de Tolstoi tal como se expresan no sólo en El Evangelio Abreviado, sino también en sus relatos literarios ayudaron al joven Wittgenstein de los años de guerra a darle forma a un sentimiento religioso acorde con el sentido que la presencia interiorizada de la muerte tenía para el literato ruso. Ahora bien, lo que respectivamente entienden por voluntad divina, a la que ambos dicen someterse, varía significativamente de uno a otro. Al cabo, mientras que Tolstoi sacraliza el amor fraterno, Wittgenstein enfatiza el dominio de sí y la salvación espiritual interior, cobrando una mayor importancia la dimensión privada del punto de vista religioso.

Palabras clave: Muerte, religión, sentido, moral, Dios, cristianismo, Tolstoi, Wittgenstein.

\footnotetext{
1 Este artículo se enmarca en los trabajos del proyecto de investigación Cultura y religión. Wittgenstein y la contra-ilustración", FFI 2008-00866 FISO.
} 


\begin{abstract}
My purpose is twofold. Firstly, I mean to show how the question of the meaning of life and the kernel of mature Tolstoy's religious feelings -which he conceives of as true Christianity- spring from his subjective experience of fear before death and anguish due to loneliness. These experiences lie at the core of his religiosity insofar as he derives from them the value of fraternity, which is essential to his altruistic and paradoxical humanist moral, which regards love among men as sacred and also as based on obedience to the will of God. Secondly, I will argue that Tolstoy's religiosity as is expressed not only in The Gospel in Brief, but also in some of his literary stories which young Wittgenstein read, helped him to shape, during the years of war, a religious feeling inspired in the significance that an internalized presence of death had for the Russian writer. Now, what they may respectively understand by God's will, to which both claim to be subject to, varies substantially. After all, Tolstoy focuses on brotherly love, while Wittgenstein emphasizes control over oneself as well as inner spiritual redemption, so that the private dimension of the religious perspective is enhanced.
\end{abstract}

Keywords: death, religion, meaning of life, morals, God, Christianity, Tolstoy, Wittgenstein.

La soledad ante la muerte, y su fantasma en vida, es una constante en los relatos del Tolstoi posterior a su crisis existencial y religiosa cuando tenía 49 años. Por citar algunos ejemplos, este aspecto es central en La muerte de Iván Ilich (18841886), Donde hay amor hay Dios (1885), Amo y criado (1894-1895), Divino y humano (1903-1905) o en Buda (1904-1908). Adopta las formas de la muerte de los próximos y queridos ("mis muertos"), la propia muerte o la de los otros anónimos; también las figuras de la enfermedad y de la vejez. Ese es el caso en Buda, donde el príncipe Siddharta se pregunta tras haber encontrado un enfermo, un viejo y un entierro en un paseo fuera de palacio:

¿Cómo pueden vivir los hombres sabiendo que a cada momento pueden enfermar, que cada instante que pasa son más viejos, se desfiguran y pierden fuerzas? También saben que pueden morir en cualquier instante, y en verdad morirán más tarde o más temprano. ¿Cómo es posible disfrutar de cualquier cosa, ocuparse de cualquier actividad? ¿Cómo es posible vivir cuando se sabe que la muerte es inevitable? Eso no puede ser...hay que encontrar una liberación?2

2 Tolstoi, L.: Buda, en Relatos, Alba, Barcelona, 2008, p. 553. 
Pero también es el caso del propio Tolstoi. Pues confiesa que a partir de un momento se sintió arrastrado por una fuerza "parecida a mi antigua aspiración a la vida, sólo que se producía en sentido inverso". ${ }^{3}$ Le embargan ideas de suicidio, le "daba miedo la vida", le parece un "absurdo" o sentirse en manos de alguien que se "ríe" de él. La descripción de su estado de ánimo supone la desaparición del "sentido racional" de cualquier acto aislado o de su vida en conjunto, una desrealización completa del mundo, una abolición del deseo. Tolstoi dice no encontrar ya alivio ni en el amor a su familia, ni en lo que consideraba arte. Con ninguna de las dos cosas puede identificarse: "Ahora no puedo dejar de ver los días y las noches que pasan volando y me conducen a la muerte. Sólo veo eso porque es la única verdad. Todo el resto es mentira". 4

Una y otra vez aparece en Confesión la pregunta por el sentido de la vida. Para responderla quedan descartadas las respuestas ofrecidas por las ciencias de la naturaleza que sólo establecen algunas relaciones causales entre fenómenos y, por tanto, no el sentido de sus acciones. Además, como veremos, la ciencia no puede develar el sentido del hombre en el universo porque toda ciencia ya reposa de antemano en una determinada concepción de las relaciones de la finitud del hombre con el universo infinito que lo rodea. Ahora bien, la pregunta por el sentido de la vida arraiga en la inminencia de la muerte o en la presencia de la muerte como anticipación interiorizada del muerto que mañana seré para mis sobrevivientes. De hecho, todo el relato de La muerte de Ivan Ilich, sólo dos años posterior a Confesión, puede verse como una anticipación interiorizada de la propia agonía de Tolstoi en cuanto observada por los que le sobrevivirán y por el propio escritor aun sano en vida. De forma que para él, como para su personaje Iván Ilich, más terrible que la muerte misma es su fantasma para el que ya se vive como futuro cadáver: "Sentía horror por lo que me aguardaba; sabía que ese horror era aún más terrible que la misma situación, pero no podía ahuyentarlo ni esperar el fin con paciencia". 5 Así, respecto de la propia experiencia de conversión dice que su "búsqueda de Dios" no era un razonamiento, sino "un sentimiento... que procedía del corazón. Era una sensación de miedo, de abandono, de soledad en medio de todo lo que era extraño para mí y, a la vez, una sensación de esperanza en encontrar la ayuda de alguien", y todo ello pese aceptar la imposibilidad de probar la existencia de Dios como Kant había demostrado. 6

Ahora bien, en todos los relatos citados, como para el propio Tolstoi, el miedo a la muerte inminente, ocasión de la conversión religiosa, siempre adquiere la forma de una revisión de la vida pasada, ahora avistada como errónea o inauténtica. Una

\footnotetext{
3 Tolstoi, L.: Confesión, Barcelona, Acantilado, 2008, p. 32.

4 Ibídem, p. 37.

5 Ibídem, p. 39, mío el énfasis.

${ }^{6}$ Ibídem, op. cit., p. 108.
} 
conversión, pues, que equivale a una resurrección no en un más allá después de la muerte sino antes de morir. Es el caso del burgués Vasili Brejunov -en Amo y Esclavo-atemorizado por una enfurecida tormenta de nieve nocturna cuando viaja para cerrar un negocio y huye egoístamente abandonando a su criado Nikita. Perdido, angustiado por el peligro y la soledad que le rodea, invoca a los santos, promete velas y misas, pero comprende que esa ritualidad vacía no le va a ayudar. El azar de su merodeo le lleva de nuevo donde yace casi congelado Nikita, que siempre había tenido el convencimiento de que dependía de alguien superior. Por tal convicción, que mata la soledad y el miedo, se siente a resguardo y no en el desierto helado de su amo. Cuando cree que se acerca el fin, Tolstoi escribe de Nikita “" ¡Señor, Padre celestial!', exclamó, y la conciencia de que no estaba solo, de que alguien le escuchaba y no le abandonaria, le tranquilizó"7. Cuando Brejunov aterrorizado vuelve a encontrarse con Nikita, se produce la conversión y "resucita". Todo el relato de su extravío en la gélida noche es una parábola de la búsqueda del sentido de la vida tal como es teorizada en Confesión. Abriga a Kikita con su pelliza y se tumba sobre él para darle el calor de su cuerpo. Siente una "alegría particular", a la vez que "unas ganas enormes de hablar con alguien de esa sensación de alegría". Brejunov va agotándose en su empeño, ya no piensa en su propio peligro y al hacer cuentas con su vida no consigue comprender cómo le interesó lo que acaparó su deseo: "Comprendió que se estaba muriendo, pero tampoco eso le apenó. Se acordó de que Nikita yacía debajo de él, de que había entrado en calor y estaba vivo, y tuvo la impresión de que él era Nikita y de que Nikita era él, y de que su vida no estaba en sí mismo, sino en Nikita". ${ }^{8}$ Brejunov muere, y Nikita es rescatado vivo por unos mujiks a la mañana siguiente. La alegría de la que quería hablar Brejunov se asocia explícitamente al amor en el caso el revolucionario Anatoli Svetlogub -en Divino y humano- cuando escribe la carta de despedida a su madre antes de subir al patíbulo donde lo ahorcarán: "Vivimos alegres y felices cuando... amamos. Sí, cuando amamos. Mientras escribía esa carta, estaba embargado de amor y me sentía bien". 9

Por tanto, en los relatos de Tolstoi el logro de esa alegría se basa en una vinculación fraterna con los hombres que se asocia con un padecer-con ellos. Cuando Tolstoi da cuenta de por qué no se suicidó alude a una fuerza, la "conciencia de la vida", que en principio consiste en una universalización, no tanto teórica cuanto emocional, de la condición humana: "esa fuerza me obligó a considerar que yo y... ese restringido círculo de científicos, ricos y ociosos al cual yo pertenecía [no] comprendía toda la humanidad y que los miles de millones de hombres que habían vivi-

\footnotetext{
7 Tolstoi, L.: Relatos, op. cit., p. 384. Las cursivas son mías.

8 Ibídem, p. 392. Mío el énfasis.

9 Tolstoi, L.: Divino y humano, en Relatos, op.cit. p. 524.
} 
do y que aún vivían fuera de ese círculo [no] eran animales, [sino] personas". 10 Porque el criterio para aquilatar quién vive con autenticidad es tanto un criterio formal cuanto material. Si Tolstoi se aparta de las gentes de su estamento no es por un desacuerdo especulativo respecto de su fe, sino por su incoherencia pragmáticomoral: "si con sus actos me hubieran demostrado que tenían una comprensión de la vida que no les hacía temer, como a mí, la pobreza, la enfermedad y la muerte, habrían podido convencerme". ${ }^{11}$ Por eso mira hacia los que perpetúan la vida por cuanto hacen posible el vivir material de la humanidad. Los "actos del pueblo trabajador" se convierten en "el único camino posible"12 para descifrar el sentido de la vida. Pues, de nuevo la muerte como gozne,

Si bien una muerte serena, sin terror ni desesperación es una rarísima excepción entre las personas de nuestra clase, una muerte tormentosa, intranquila e infeliz es una excepción rarísima en el pueblo. 13

Ahora bien, esas gentes tienen una fe determinada. Luego esa fe debe ser la que exprese una correcta relación con el universo y su principio. Esa es la razón de que Tolstoi afirme la primacía de la fe sobre el Dios al que se le profesa: "es preciso determinar primero la fe y luego a Dios, y no a la inversa". 14 Aspecto éste del todo ininteligible si se pensara que la actitud religiosa es una actitud meramente especulativa. No: "la fe es la fuerza de la vida. Si un hombre vive es porque cree en algo. Si no creyera que debe vivir por algo, no viviría". ${ }^{15} \mathrm{La}$ fe, antes que otra cosa, es un estar en el mundo, un actuar de cierta manera, no un pensar.

Como es sabido Tolstoi se dedicó a deslindar en los evangelios lo que consideraba el núcleo de esa fe, el verdadero cristianismo. 16 Pero, en definitiva, lo que se desgaja de esa tarea de crítica bíblica ya lo había encontrado por el camino que he señalado. Pues es importante distinguir en este punto dos métodos: por un lado, el camino del descubrimiento de la fe, el cómo de la "revelación" y, por otro, el de la exposición sistemática de su concepción del verdadero cristianismo que hace en sus textos de crítica teológica. En cuanto al cómo de la revelación, discurre así: del

\footnotetext{
10 Tolstoi, L.: Confesión, op.cit. p. 78.

11 Ibídem, p. 94.

12 Ibídem, p. 99.

13 Ibídem, p. 98.

14 Ibídem, p. 88.

15 Ibídem, p. 88.

16 En Crítica a la teología dogmática (1879-1880), La concordia y la traducción de los cuatro Evangelios (1892-1894), El Evangelio abreviado (1890), Mi religión o ¿Cuál es mi fe? (1884) y El Reino de Dios está entre vosotros (1890-1893) y tantos otros escritos hasta el final de su vida, algunos de menor extensión pero no menor importancia, como Religión y Moral o ¿Qué es la religión y en qué consiste su esencia?
} 
deseo de exorcizar la angustia y la soledad que el miedo a la muerte comporta, a la aceptación de los que afirman la vida en sus actos; de la fe en la vida de éstos, a la inspección de las reglas morales más generales que rigen su vivir y morir; y de ahí (en cuanto toda moral expresa un punto de vida religioso, una determinada concepción de la relación que mantenemos con el universo infinito y su principio), a Dios a cuya voluntad debo someterme. Pero la voluntad de Dios, en cuanto Dios es la afirmación de la vida, puede leerse de hecho en los rasgos más generales de la forma en que vive aquel pueblo humilde cuyo trabajo sostiene la vida de la humanidad.

Se impone pues aclarar la relación entre religión y moral recién señalada. Lo haré ahora no en el orden del descubrimiento, sino en el orden de su exposición dogmática. Para Tolstoi todo hombre, no importa que lo quiera o sea consciente de ello, es religioso. Porque las religiones son distintas formulaciones histórica y etnográficamente determinadas de la respuesta a la pregunta de en qué relación me encuentro como ser finito con el universo infinito que me rodea y su principio. ${ }^{17} \mathrm{Y}$ tal variedad puede reducirse a tres tipos: la religión salvaje, la pagana, social o civil y la cristiana verdadera. Los dos primeros tipos se guían por un principio egoísta: lo que da significado a la vida es la búsqueda del bien personal. La diferencia entre el primer tipo y el segundo es que, en el caso de la pagana, social o civil el mayor bien posible se persigue a través de lo que es bueno para un determinado grupo: "la familia, la tribu, el pueblo, el Estado e incluso la humanidad (ensayo de una religión positivista)"18; y todo ello "independientemente de la pregunta por el daño causado por esta búsqueda al bien de otras criaturas". ${ }^{19}$ Que no nos ofusquen los términos, Tolstoi considera como religión pagana el cristianismo de Estado, católico u ortodoxo, tal como fue diseñado, dice, por San Pablo y San Agustín, porque pretenden la salvación, "es decir, la consecución del mayor bien del individuo en un vida futura". ${ }^{20}$

Por el contrario, la verdadera concepción cristiana considera que "el sentido [de la vida] está por entero contenido en la obediencia a la voluntad que lo ha creado, a él [el hombre] y al mundo entero, no para que alcance sus propios fines, sino los de esa voluntad creadora". ${ }^{21}$ Que las ciencias no nos puedan decir nada al respecto se debe a dos razones: una de orden psíquico y la otra de orden lógico. En cuanto la raíz de la apertura religiosa es del orden del sentimiento (del temor a la muerte, la soledad, el abandono...), la ciencia, y la filosofía como parte de ella, nada pueden decir; porque estudian los fenómenos desde la razón pura sin tener en cuenta los sentimientos y emociones del estudioso, siendo así que el hombre también es

17 « L'essence de toute religion consiste seulement en une réponse à la question: pourquoi est-ce que je vis et dans quel rapport suis-je avec l'univers infini qui m'entoure? » Tolstoi, L.: Religion et Morale, Paris, Typography A. Davy, 1898, pp. 12-13.

18 Ibídem, p. 15.

19 Ibídem, p. 14.

20 Ibídem, p. 21.

21 Ibídem, p. 17. 
"una criatura susceptible de sentir, de sufrir, de gozar, de temer y de esperar". ${ }^{22}$ Con todo, la razón más poderosa de la incapacidad de la ciencia para establecer el sentido de la vida es de orden lógico. Pues la ciencia nunca ha estudiado más que algunos de los objetos de conocimiento posibles; pero el interés por éstos o aquéllos otros -los fines de la investigación- se establece desde la relación que el hombre mantiene con el universo, previa al conocimiento efectivo, y tal cosa es lo que define lo esencial de la religión. Así, la ciencia pagana, fomentada por el Renacimiento, tiene como norte estudiar las condiciones en las que los hombres obtienen su mayor bien personal, o los fenómenos naturales a partir de cuya maestría lo obtendrá; la ciencia talmúdica judía consiste en el estudio de las cláusulas que el hombre debía respetar para mantener el pacto establecido con Dios como pueblo elegido, etc.

Ahora bien, si no es desde la ciencia ¿de qué manera puede establecerse esa vinculación verdadera con el universo que me permita reconocerme como el "instrumento de una voluntad superior que [me] ha enviado al mundo para realizar la obra que [me] ha asignado"? ¿Cómo puedo "aprender a conocer esa voluntad y adecuarme a ella"? 23 Siendo así que todos los otros conocimientos se desprenden del punto de vista religioso, anterior en el orden lógico, "no podemos dar la definición [de tal método] porque no tenemos para ello los instrumentos que sirven para definir". ${ }^{24}$ Cabe pues rescatar lo que el lenguaje teológico llama Revelación. Lo importante no son las determinaciones históricas -por qué se dio allí o a quién- tampoco la inteligencia personal, sino "las cualidades pasivas del corazón: renuncia a las vanidades del mundo, conciencia de la propia nada desde el punto de vista material, sentimiento de justicia"; 25 esas son las condiciones necesarias para "recibir la manifestación de la inteligencia infinita". ${ }^{26}$

$\mathrm{Si}$ "el sencillo pueblo trabajador" de Rusia no temía a la muerte, si sus actos mostraban una vida con sentido por cuanto la afirmaban gozosamente, entonces no hay más que inspeccionar su moral en sus trazos más generales para aquilatar la verdadera religión. Pues, como la ciencia, también los tipos de moral expresan una determinada relación con el universo infinito y su principio. Es más, y esto es importante, la moral está ya de antemano implicada en la religión:

La moral no puede ser independiente de la religión porque no solamente es una consecuencia de la religión (es decir, de la relación en la cual el hombre reconoce estar con el universo), sino que se encuentra ya implicada en la religión. Toda religión es una respuesta a la cuestión: ¿Cuál es el sentido de mi vida? Y la respuesta religiosa implica siempre un cierto número de exigencias morales que, a veces, pueden nacer solamente

\footnotetext{
22 Ibídem, p. 24.

23 Ibídem, p. 24.

24 Ibídem, p. 26.

25 Ibídem, p. 28

26 Ibídem, p. 26.
} 
después que el sentido de la vida haya devenido aparente y que, a veces, pueden existir anteriormente. 27

Ahora bien, de nuevo: ¿Cómo reconozco la voluntad de Dios, principio del universo al que debo someterme? Es más: ¿En qué forma Dios es principio, qué quiere decir aquí "creador"? 28 De hecho, si atendemos a su afirmación de que la moral está ya de antemano implicada en la religión, de que a veces las virtudes morales se manifiestan incluso antes de conocer el sentido de la vida, una dirección hacía donde mirar son aquellas cualidades pasivas del corazón, a la sensibilidad moral, que permiten y facilitan la revelación: renuncia a lo superfluo, conciencia de la precariedad vital y sentimiento de justicia. La sensibilidad moral que hace posible el mensaje divino acaba convertida en el propio mensaje. Son innumerables los pasajes donde Tolstoi afirma que la voluntad divina quiere que consideremos a todos los hombres iguales, que la voluntad divina "consiste en que el hombre debe consagrar su vida al servicio de los hombres." 29 Una fraternidad que incluye el perdón como una forma del amor. Nikita, paradigma de la vida campesina que cabe emular, muere pidiéndole perdón a su mujer y perdonándola por su relación adultera con un tonelero; también Iván Ilich perdona a su mujer inmediatamente antes de morir. Una de las conclusiones finales de la novela Resurrección es que todo el sistema penal zarista es un infierno de corrupción administrativa y moral por no seguir la respuesta de Cristo a Pedro cuando éste pregunta cuántas veces cabía perdonar al que le hubiera ofendido: "consistía en perdonar, siempre, a todos, perdonar una infinidad de veces, porque no existe gente que no sea culpable y, por tanto, pueda castigar o corregir a otros." 30

En una carta escrita el último año de su vida a un obrero de Baku, Tolstoi considera digno de ser "olvidado por completo" lo mucho que la Biblia habla sobre "el Dios que crea el mundo y la especie humana y que castiga a todo al que le desobedece". Al final de la carta, vuelve sobre la supuesta distribución divina de premios y castigos y afirma que nuestra vida sólo tiene sentido cuando vivimos de acuerdo con el mandamiento de amarnos los unos a los otros. Con todo, la razón para cumplir ese mandamiento no es el eventual castigo que pudiéramos recibir en otra vida ultramundana, sino que de ignorarlo "la vida se hace dolorosa, problemática, mala". La vida aquí, la única, pues, escribe Tolstoi, "da la impresión de que los premios y los castigos que puedan merecer nuestras acciones los recibiremos en esta vida, puesto que no podemos conocer ninguna más".

\footnotetext{
27 Ibídem, p. 35. El primer énfasis es de Tolstoi, el segundo mío.

28 Recuérdese que lo distintivo del cristianismo es la afirmación de que "el sentido [de la vida] está por entero contenido en la obediencia a la voluntad que lo ha creado, a él [el hombre] y al mundo entero, no para que alcance sus propios fines, sino los de esa voluntad creadora". Cf. Supra.

29 Tolstoi, L.: Religion et morale, op.cit. p. 40.

30 Tolstoi, L.: Resurrección, Barcelona, Vertical de Bolsillo, 2008, p. 615.
} 
Cierto, Tolstoi da razones de por qué considera el alma inmortal, lo cual no equivale a una vida en común de los muertos tras la muerte. El tiempo sólo existe para el mundo material, por tanto, también para el cuerpo del hombre que siente y manipula el mundo externo. Pero el alma es atemporal por inmaterial. Adhiriendo a un dualismo ontológico radical, hay en Tolstoi una escisión aun más profunda que en Descartes entre cuerpo y alma. Porque el alma es dicha "residir" en el cuerpo sin mayor ni ulterior consideración. El alma, combinando ahora su cartesianismo con una teoría lockeana (también más mentalista que la del propio Locke), no es más que la identidad personal, una identidad de la que queda fuera toda consideración corporal y cuyo principio de unidad es que yo pueda referirme a los contenidos de conciencia pasados como asociados o en continuidad con los actuales en una única corriente de conciencia cuyo hilo es la memoria:

El yo del que hablé hace setenta años es el mismo yo al que me refiero ahora... Yo siempre soy, pase lo que pase, mi alma, el yo al que me refiero, se mantiene igual y es inmaterial...Para el alma el tiempo y el espacio y el mundo material no tienen ninguna realidad. Así que no podemos preguntar realmente lo que le pasará al alma o a dónde irá después de la muerte, porque la expresión pasará indica tiempo y la palabra dónde indica espacio. 31

Ahora bien, si Dios no castiga ni premia, si Dios no ha creado ni el mundo ni la humanidad ¿en qué forma es principio? En esa misma carta, Tolstoi afirma rotundamente que "sólo podemos decir que eso que llamamos vida es simplemente el principio divino". 32 Por ello, la fraternidad, bajo las diferentes formas del amor y el perdón, es sagrada. Porque afirma la vida y puede decirse entonces que todo lo que facilite la alegría de vivir es divino, cumple la voluntad de Dios.

Como es sabido, esta sacralización de los vínculos fraternos conlleva una moral pública. Conocida es su lucha contra la propiedad de la tierra, por la reducción de la jornada laboral, la instrucción de las masas campesinas, la denuncia de la violencia organizada del estado en general y de los sistemas judiciales y penitenciarios en particular, también sus estudios al respecto en escritos de índole política, como $L a$ esclavitud de nuestro tiempo. ${ }^{33}$ Pero toda esa acción pública debe estar siempre pre-

31 Tolstoi, L: "Carta a Pyotr Melnikov, un obrero de Baku del 22 de enero de 1910", en Parini, J. La última estación en la vida de Tolstoi, Barcelona, Península, 1995, pp. 21-22.

32 Loc.cit.

33 En Resurrección alude a las teorías de Lombroso, Garofalo, Ferri, List, Maudsley y Tardé, etc. Y aunque, aquí y allá, se aluda a ellas sin mencionarlas, en un momento resume su temática como "si el hombre tiene o no libre albedrío, si se puede reconocer a un criminal por la medida de su cráneo, etcétera; el papel que desempeña la herencia en la delincuencia; si existe la inmoralidad innata; qué es la moral, la locura, la degeneración y el temperamento; la influencia sobre el crimen del clima, la alimentación, la ignorancia, la limitación, el hipnotismo, las pasiones...". Todas ellas -dice- no pueden contestar a la pregunta moral de "Por qué razón y con qué derecho unos hombres encierran, atormentan, 
sidida por el principio de no dañar a los demás. O dicho de otra manera: la no violencia es otra de las formas de la fraternidad que su religión y moral fundamenta. Lo cual no obsta para que la expresión pública, o política, de su moral vulnere la legalidad; pues si no todo lo legal es moral, está fuera de duda para Tolstoi "que todo acto que hace dar a la moral un paso adelante consiste siempre en una transgresión del orden establecido". ${ }^{34}$

Es hora de hablar del joven Wittgenstein. Un año antes de que empezara la Primera Guerra Mundial, el futuro autor del Tractatus escribió a Bertrand Russell contándole sus trabajos sobre la lógica. Pero no sólo, en la carta también hablaba de sus sentimientos:

Aún no he resuelto el problema de los tipos, aunque tengo todo género de ideas que me parecen muy fundamentales. Pero crece en mí día a día el sentimiento de que moriré antes de poder publicarlas, y por ello mi mayor deseo sería comunicarle a usted todo lo que hecho hasta ahora lo más pronto posible. 35

Tan apremiante era ese sentimiento que a las dos semanas, a principios de octubre, ya estaba de vuelta de sus vacaciones en Noruega para visitar a Russell. Desde hacía un tiempo a Wittgenstein lo embargaba un sentimiento de muerte, podríamos decir, por implosión. Es decir, un sentimiento no basado en indicio racional alguno de enfermedad ninguna, tampoco de un peligro exterior cercano o verosímil. Ese sentimiento de muerte "desde dentro" es acorde con la obsesión por el suicidio que lo atormentó según sus biógrafos entre 1903 y 1912.36 Incluso después de la guerra, Wittgenstein reconoce en una carta a Engelmann de 1920 que "he pensado sin cesar en quitarme la vida y todavía ahora esa idea fantasea dentro de mí. Estoy total \& absolutamente hundido". ${ }^{37}$ En su respuesta a la contestación de Engelmann Wittgenstein insiste en que se encuentra en una situación "en la que ya he estado a menudo en mi vida y que me resulta muy penosa", se muestra de acuerdo en que el suicidio "es siempre una indecencia", "que no se puede querer en absoluto el propio aniquilamiento" y remite su ánimo autodestructivo a la falta de fe. ${ }^{38}$ Por tanto,

deportan, azotan y matan a otros hombres cuando ellos son exactamente iguales que aquéllos a quienes torturan, azotan y matan”. Tolstoi, L.: Resurrección, op. cit., p. 438.

34 Ibídem, p. 44.

35 Wittgenstein, L: Cartas a Russell, Keynes y Moore, Madrid, Taurus, 1979, p. 34. El primer énfasis es mío, el segundo es de Wittgenstein.

36 Véase Monk, R.: Ludwig Wittgenstein, el deber de un genio, Barcelona, Anagrama, 1994, p. 40.

37 Wittgenstein-Engelmann, Cartas, Encuentros, Recuerdos, (Edición de Ilse Somavila), Valencia, Pretextos, 2009, carta 65, p. 76.

38 “Naturalmente, todo desemboca en que no tengo fe!”, Ibídem, carta 67, p. 79. 
uno de sus acuerdos más generales con Tolstoi es que es consustancial a la fe mantener la esperanza, la capacidad de ver que tiene sentido aferrarse a la vida.

Entre la carta a Russell y la carta a Engelmann media el gran conflicto europeo que implicó a EEUU y las colonias de las potencias europeas. Un conflicto de tal magnitud destructiva y muerte masiva que la historiografía reciente lo considera una quiebra antropológica, también una involución civilizatoria. Un conflicto que, inaugurando la guerra tecnificada moderna, dio una profundidad inédita a lo bélico: tierra, aire, superficie y profundidad marítima. Una guerra donde la aparición de armas abstractas permitió matar en masa y a distancia, contribuyendo así a difuminar para siempre la distinción combatiente/no combatiente. Una guerra que, en expresión del general Ludendorff, debía ser considerada una "Guerra Total" y que impulsó a Freud a reformular su teoría de las pulsiones e introducir a Tánatos junto a Eros como las dos pulsiones universales más generales. Un conflicto, por fin, que supuso un largo y complicado periodo de duelo en Europa. Expresión no menor del cual fue la construcción de miles de memoriales, cenotafios, lápidas, cementerios de guerra...que plagaron todos los rincones de las naciones combatientes, a la vez que se publicaban una miríada de recuerdos del frente, libros de memorias, diarios, cuadernos de notas, novelas escritas por veteranos, etc.

Wittgenstein participó en esa guerra y sabemos por sus biógrafos y sus diarios que corrió graves riesgos y peligro mortal. En más de una ocasión tras batallas o retiradas sangrientas anotó en sus diarios haber visto "cosas horribles". Además, si sus tres hermanos varones mayores se suicidaron, uno de ellos -Kurt- lo hizo, no muy lejos de donde entonces combatía Wittgenstein, por razones directamente ligadas al conflicto bélico. ${ }^{39}$ Pues bien, en la proposición 6.4311 del Tractatus podemos leer: "La muerte no es ningún acontecimiento de la vida. La muerte no se vive".

Lo cual no deja de ser pasmoso en el contexto en el que se escribió y junto a la inmensa literatura escrita por los que sí creían que la muerte había sido el gran acontecimiento de sus vidas, que cambiaron para siempre al haber vivido la de sus amigos, familiares, camaradas... y también la de los enemigos a quienes se la habían dado. Wittgenstein podía haber dicho " $m i$ muerte no es un acontecimiento de mi vida. No viviré $m i$ muerte o no tendré experiencia de $m i$ muerte". Lo cual ya lo había afirmado Epicuro y, en cualquier caso, supone una concepción muy limitada de la muerte que se restringe al instante del propio morir. Que Wittgenstein lo for-

39 O bien se suicidó porque no pudo soportar que sus tropas se le amotinaran, o bien se quitó la vida tras rebelarse permitiendo desertar a los soldados bajo su mando cuando le dieron una orden que suponía su muerte inútil en los últimos días antes del armisticio en el frente italiano. Una versión familiar decía que se había suicidado como tantos otros oficiales austriacos en las veinticuatro horas posteriores al armisticio del 3 de noviembre que puso fin a la guerra. Los biógrafos -y distintos miembros de la familia- dan varias versiones cf. Monk, R., op.cit., pp. 28 y ss; y Waugh, A.: La Familia Wittgenstein, Barcelona, Lumen, 2009, pp. 176. 
mulara de la forma en que lo hace en esa "proposición" del Tractatus se debe a su peculiar posición respecto del solipsismo, asunto que no trataré. Pero por más que dicha afirmación se deba en último término a una muy austera teoría del significado, no por ello, insisto, es menos pasmosa y sorprendente en el contexto histórico que la hizo.

Sin embargo, lo reprimido retorna, especialmente los sentimientos y emociones del "sujeto empírico" Wittgenstein. Y lo que no se dejaba decir en el Tractatus, se anota libremente en la escritura íntima o en las conversaciones privadas. $Y$ así en la anotación del 7.10.1914 de los Diarios Secretos encontramos una afirmación de índole tolstoiana:

Aún no acierto a cumplir con mi deber simplemente porque es mi deber, ni a reservar mi persona entera para la vida del espíritu. Puedo morir dentro de una hora, puedo morir dentro de dos horas, puedo morir dentro de un mes o dentro de algunos años. No puedo saberlo y nada puedo hacer ni a favor ni en contra: así es esta vida. ¿Cómo he de vivir, por tanto, para salir airoso en cada instante? Vivir en lo bueno y en lo bello hasta que la vida acabe por sí misma. ${ }^{40}$

De momento subrayaré la conexión entre ese sentimiento de la posibilidad de una muerte inmediata, también de la muerte sentida en antefuturo, y la idea de una vida buena, que aquí es dicha como "vivir en lo bueno y en lo bello" (cómo quepa entenderlo, lo veremos más adelante). Todos los Diarios Secretos, unas veces con mayor, otras con menor insistencia, están recorridos por esa conexión. El 4 de mayo de 1916 anota:

Tal vez mañana me incorpore a los exploradores, a petición mía. Entonces comenzará para mí la guerra ¡Y puede ser que también la vida! Tal vez la cercanía de la muerte me traiga luz a la vida. iQue Dios me ilumine! Soy un gusano, pero por obra de Dios me transformo en persona. Que Dios me asista. Amén!.

Cinco días después, concluye rotundamente:

Es la muerte, y no otra cosa, lo que da su significado a la vida. ${ }^{41}$

La última cita muestra rotundamente lo que quiero subrayar: que en Wittgenstein encontramos la matriz tolstoiana de la apertura religiosa. Es "la cercanía de la muerte", cuya aparición abrupta y azarosa en el frente es muy verosímil, la ocasión de escrutar el sentido de la vida, de llegar a vislumbrar el comienzo de

\footnotetext{
40 Wittgenstein, L: Diarios secretos, Madrid, Alianza Universidad, 1991, pp. 65-7.

41 Ibídem, pp.147-149.
} 
una vida nueva, de una "resurrección" (el comienzo de la guerra quizá sea el comienzo de "la vida"): "Ahora se me presentaría la ocasión de ser una persona decente, pues me enfrento cara a cara con la muerte", ${ }^{2}$ dice después de las primeras experiencias de combate. Y esa búsqueda del sentido de la vida también está en Wittgenstein, como en Tolstoi, ligada a Dios con cuya asistencia dice poder transformarse de animal en persona.

Porque también para Wittgenstein, como para Tolstoi, el miedo a la muerte es el criterio para determinar lo errado de la vida que se vive o se ha vivido. Y Wittgenstein, a pesar de alguna anotación, sí tenía miedo a la muerte. 43 El 6 de mayo de 1916 anota: "En constante peligro de muerte... De cuando en cuando siento miedo ¡Esta es la escuela de la falsa concepción de la vida...!”, y el 29 de julio del mismo año aún es más explícito:

Ayer fui tiroteado. Sentí miedo. Tuve miedo a la muerte. ¡Lo que ahora deseo es vivir! Y resulta difícil renunciar a la vida cuando se le ha tomado gusto. Pero precisamente eso es "pecado", vida irrazonable, falsa concepción de la vida. De cuando en cuando me convierto en un animal. Entonces soy incapaz de pensar en ninguna otra cosa que no sea comer, beber, dormir ¡Horroroso! Y entonces sufro también como un animal, sin posibilidad de salvación interior. En esos momentos estoy entregado a mis apetitos y a mis aversiones. En esos momentos es imposible pensar en una vida verdadera. ${ }^{44}$

Era el parecer de Tolstoi que el estar en pecado equivalía al no cumplimiento o realización de todo lo que habría podido y debido hacer un hombre. ${ }^{45}$ En un sentido acorde, para Wittgenstein el pecado es visto aquí como pura inercia vital, como un aferrarse instintivo a la vida sin preocuparse de lo que en ella cada uno puede y debe cumplir. Además, de nuevo como en Tolstoi, si la distinción entre vida verdadera y vida errada tiene una formulación religiosa - estar o no en pecado-, no por ello ese "estar en pecado" carece de una traducción psicológica. Decía Tolstoi -en la carta al obrero de Baku- que la razón para cumplir la voluntad divina no era el eventual castigo que pueda recibirse en otra vida posterior a la muerte, sino que de ignorarla la vida se hacía dolorosa, problemática y mala. Así, los personajes de sus relatos populares, el amo de Nikita, el estudiante revolucionario..., todos dicen experimentar alegría cuando por fin deciden vivir según el mandato de la voluntad

\footnotetext{
42 Ibídem, 15 de septiembre de 1914, p. 55.

43 Mucho se ha dicho sobre que el propio Wittgenstein afirmara tras la guerra que se había alistado voluntario buscando la muerte. Por ejemplo, el propio W. Baum, editor de los Diarios Secretos, en nota al pie a la entrada del 15 de abril de 1916. Sin discutir este aspecto como merece, donde caben incluso consideraciones que atañen a su generación y la guerra, creo que su encaramiento con la muerte tiene el sentido religioso y moral aludido.

44 Ibídem, p. 155.

45 Tolstoi, L. Religion et Morale, op. cit, p. 11.
} 
divina. Y ese también es el caso de Wittgenstein. Por los mismos días de las anteriores anotaciones citadas, afirma: "Sigo viviendo en pecado, es decir, infeliz. Estoy de mal humor, sin alegría. Vivo en discordia con todo mi entorno".46 También para Wittgenstein, pues, ponerse en manos de Dios, someterse a su voluntad -"hágase tu voluntad" es una expresión casi obsesivamente reiterada en los Diarios Secretoses condición de paz interior, de alegría. Ante la pregunta “¿Más cómo llegar a la paz interior? [se contesta] ;SOLO si llevo una vida grata a Dios! Sólo así es posible soportar la vida";47 "¿Qué Dios me mejore! Así estaré también más contento"48, "QQuiera Dios conservarme alegre de ánimo!".49

En el mismo sentido creo que se debe interpretar la anotación donde Wittgenstein encara un punto de vista nihilista con ocasión de su lectura de un tomo de las obras de Nietzsche que incluía El Anticristo. Piensa que en su crítica al cristianismo también hay algo de verdad. Y tras afirmar "que el cristianismo es la única vía segura a la felicidad", se pregunta por qué no desdeñar esa felicidad, si no sería mejor la desdicha de perecer en una lucha sin esperanza contra "el mundo exterior". Reconoce que una vida así carece de sentido ¿pero por qué no llevar una vida carente de sentido? Wittgenstein no responde a su propia pregunta de si una vida así sería indigna. Lo que sí sabe es que una vida así sería para él infeliz, sin contento ni alegría: "¿Qué he de hacer entonces para que no se pierda mi vida? He de ser siempre consciente de él -siempre consciente del espíritu". 50

Sin embargo, a pesar de esta concordancia con Tolstoi, hay entre ambos diferencias relevantes, tanto en la concepción de la vida buena cuanto en el modo de la "redención".

Si en el caso de Tolstoi el sentido de la vida estaba por entero contenido en el obedecer la voluntad divina, cifrada en una sacralización de los vínculos fraternos y "no para que [el hombre] alcance sus propios fines", en el caso de Wittgenstein de lo que se trata es de una "salvación interior". En él, llegar a cumplir lo que puede y debe realizar, es decir, superar el estado de pecado, no es tanto una afirmación del vínculo amoroso con los otros, cuanto un dominio de sí -de "sus apetitos y aversiones", de sus instintos y pasiones- por la fuerza del espíritu. Pues también son muy numerosas las anotaciones de los Diarios donde Wittgenstein conecta la ayuda de Dios para alcanzar la vida buena con su debilidad de espíritu: "Pero yo soy, desde luego, una persona débil. Pero el espíritu me ayuda". ${ }^{51}$ Creo que una de las diferencias entre Tolstoi y Wittgenstein se muestra si contraponemos dos asertos: uno, el

\footnotetext{
46 Ibídem, 11 de agosto de 1916, p. 157.

47 Ibídem, 6 de mayo de 1916, p. 149.

48 Loc. cit. énfasis mío.

49 Ibídem, 6 de agoste de 1916, p. 157, énfasis mío.

50 Ibídem, 8 de diciembre de 1914, p. 109.

51 Ibídem, 16 de julio de 1916, p. 155.
} 
de la anotación del 16 de mayo de 1916 de los Diarios Secretos; el otro, una de las conclusiones del revolucionario Anatoli Svertlogub en el relato Divino y humano:

Soy una persona débil, pero Dios me ha sostenido hasta ahora. Alabado sea Dios por toda la eternidad. Amén. Hago entrega de mi alma al Señor. 52

Dar mi alma, no ponerla a salvo, sino entregarla. En eso consiste la alegría, en eso consiste la vida. 53

En ambas hay una entrega a Dios, un ponerse en sus manos. Pero en el caso de Tolstoi la entrega prima sobre la propia salvación del alma; para Wittgenstein la entrega es por mor de la propia salvación, de una salvación interior que depende del dominio de sí por la intervención del "espíritu".

Pero de nuevo hay semejanzas y desemejanzas entre ambos respecto qué sea el espíritu o principio divino. Se ha dicho con razón que este término, tal como aparece en los Diarios Secretos, es de filiación tolstoiana. El propio Wittgenstein la afirma la primera vez que "espíritu" aparece (muy pronto, pues, tras su alistamiento). Temiendo no cumplir bajo el fuego correctamente con su deber, se dice: "Una y otra vez me repito interiormente las palabras de Tolstoi: 'El hombre es impotente en la carne, pero libre gracias al espíritu’ ¡Ojalá que el espíritu esté en mí!’. ${ }^{54}$ Y cuatro días después subraya que el hombre es "únicamente [libre] gracias a él". 55 Y, en efecto, el subtítulo del cap. I de El Evangelio Abreviado de Tolstoi -el famoso libro que Wittgenstein compró en una librería de Tarnów cuando patrullaba en el Goplana con base en Cracovia- reza: "El hombre es hijo de Dios, impotente en la carne y libre gracias al espíritu [Der Mensch ist ein Sohn Gottes, ohnmächtig im Fleische und frei durch den Geist]. ${ }^{56}$ Ahora bien, que la filiación sea en este punto tolstoiana no quiere decir que haya total coincidencia. Es más, en lo tocante al carácter de su respectiva religiosidad hay una distancia notable, por más que para ambos encontremos una divinización del espíritu.

Diferencia que se manifiesta en la polisemia, también se ha subrayado, del término "Espíritu", tanto en los Diarios Secretos, como en Culture and Value y los dia-

\footnotetext{
52 Ibídem, p. 151.

53 Tolstoi, L.: Divino y humano, en Relatos, op. cit. p. 519.

54 Wittgenstein, L.: Diarios Secretos, op. cit. p. 53, 12 de septiembre de 1914.

55 Ibídem, p. 55. Énfasis mío.

56 "El hombre es hijo de Dios, débil de carne y libre de espíritu", dice la traducción española de Iván García Sala. KRK, 2006, p. 63. Gracias a J.B. Llinares por hacerme reparar en la estricta coincidencia entre la anotación de Wittgenstein y la versión alemana que leyó de El Evangelio Abreviado. Véase su "Notas sobre la religión en el maduro Tolstoi y sobre la lectura wittgensteiniana de Kurze Darlegung des Evangelium (El Evangelio abreviado)" La Torre del Virrey, serie 7º 2010/3.
} 
rios (1930-32 y 1936-1937) conocidos como Movimientos del Pensar. ${ }^{57}$ Es cierto que en lo que aquí nos concierne Wittgenstein comparte con Tolstoi un sentido de "espíritu" en el que el término refiere a la identidad personal de cada cual, el núcleo más radicalmente distintivo de cada subjetividad. En Wittgenstein ello incluye la potencialidad creadora, los dones intelectuales, aquello en lo que más íntimamente me reconozco y a lo cual siempre aspiro, un ideal del yo, si lo quisiéramos decir en fraseología freudiana; todo lo cual, por cierto, incluye la componente cultural particular (Kultur) en la que se ha formado y de la que participa y que, también, subsume el canon de las grandes obras de arte que le es propio. Por ello para Wittgenstein, cuando menos a la altura de los Diarios Secretos, el "espíritu" que debe ayudarle a vivir decentemente se invoca de muy diferentes formas según se esté aludiendo a su dimensión personal o transpersonal. En ocasiones se desea tener más fuerte (“iiiOh si mi espíritu fuera más fuerte!!!”); en otras le ayuda en su debilidad (Soy una persona débil, "pero el espíritu me ayuda"); o le da el coraje viril necesario ante el peligro ("Pensamientos cobardes, titubeos miedosos, temores angustiados, quejas femeniles no cambian la miseria, iNo te hacen libre!); 58 el espíritu es también aquello en lo que uno se resguarda cuando acucia la penuria material y el malestar emocional (entonces "se vuelve hacia el espíritu", o está "dentro de mí contra mis depresiones");59 algo que no debe perder a riesgo de disolverse (“iiiNo perderse a sí mismo!!!!”);60 a lo que debe dedicarse por entero, que le hace libre porque le desliga de las contingencias exteriores y le guarece (" $i C o n$ tal de que esté vivo el espíritu! Él es el puerto seguro, protegido, apartado del desolado, infinito, gris mar de los acontecimientos." ${ }^{61}$....Cierto, Wittgenstein diviniza ese espíritu, que en ocasiones identifica con Dios, porque es principio de la vida auténtica. Pero ese espíritu es un principio divino que difiere del concebido por Tolstoi en un sentido, creo, decisivo.

El Dios de Tolstoi es principio porque, al identificarse con la vida, su voluntad radica en que afirmemos tanto la existente cuanto su reproducción; de ahí el mandato del amor fraterno, puesto que éste la hace posible. Este respecto del principio divino, que en Tolstoi es completamente nuclear, en Wittgenstein está subordinado a su salvación interior. Si Tolstoi miraba al sencillo pueblo ruso en pos de su fe religiosa y de las virtudes morales implicadas que le hacían vivir y no sentir ni miedo,

\footnotetext{
57 Pero aquí me limitaré a los diarios de la guerra dado el periodo que me ocupa. Véase el ensayo de Reguera, I. "Cuadernos de Guerra", pp. 95 y ss., en Wittgenstein, L. Diarios Secretos, op.cit; también Sanfélix, V. "Una filosofía del espíritu. Wittgenstein y la cuestión judía”, en Mariano Rodríguez (ed), La mente en sus máscaras, Biblioteca Nueva, Madrid, 2005, que lleva su análisis a textos como Cultura y Valor y Movimientos del Pensar.

58 Wittgenstein, L. Diarios Secretos, op. cit., 20 de febrero de 1915, p. 127.

59 Ibídem, 20 de octubre de 1914, p. 75.

60 Ibídem, p. 43.

61 Ibídem, 13 de diciembre de 1914, p. 111.
} 
ni soledad, ni angustia ante la muerte, Wittgenstein dedica las más despectivas expresiones hacia la clase de tropa y prácticamente todos los que le rodean, salvo una notable tendencia favorable hacia los oficiales. Es inagotable la lista de invectivas a lo largo de todos los Diarios Secretos: banda de cochinos, hatajo de bribones, groseros, estúpidos, insolentes, malvados, carentes de corazón, imposible encontrar en ellos un rastro de humanidad, máscaras grotescas, gentuza vulgar, le dan asco, grises sinvergüenzas, simples larvas, cada palabra que oye de ellos es una grosería... No son parafraseos míos, son expresiones literales de Wittgenstein que puntean todas sus anotaciones. La última anotación, del 19 de agosto de 1916, son dos líneas donde se repite "¡Rodeado de ordinariez! Rodeado de ordinariez”. ${ }^{62}$ En cambio, salvo en una ocasión, todas las menciones a los oficiales son de tono totalmente diferente. 63

No creo que sea una anécdota, es un síntoma de un aristocratismo del espíritu -que tiene una componente estamental concomitante debido al concepto de Kultur que Wittgenstein asume- totalmente lejano de Tolstoi y su divinización del amor fraterno. Porque la libertad que confiere el espíritu es para alejarse del mundo y de sus contingencias ("El ser humano no debe depender del azar. Ni del favorable ni del desfavorable"64), para hacerse independiente no sólo de las cosas, sino aun más de las personas ("Es más fácil ser independiente de las cosas que de las personas ¡Pero también hay que poder lograr esto!”). 65 Pues si no debía perderse a sí mismo recogiéndose en el espíritu, es precisamente en la entrega a los otros donde más fácil es perderse: “...ejecutar con humildad las tareas, y, por amor de Dios, ${ }_{i i}{ }^{N}$ No perderse a sí mismo!!!! Pues cuando más fácilmente se pierde uno a sí mismo es cuando quiere darse a los demás". 66

Hay una anotación de los Diarios Secretos que expresa bien la distancia con el punto de vista de Tolstoi, es una cuestión de acento, pero un acento decisivo:

¡Haz las cosas lo mejor que puedas! Más no puedes hacer: y conserva la alegría. Deja que los otros se basten a sí mismos. Pues los otros no te apoyarán, o sólo por breve tiempo (luego les resultarás pesado). Ayúdate a ti mismo y ayuda a los demás con toda tu fuerza. Y al hacerlo ¡conserva la alegría! ¿Pero cuanto fuerza se necesitará para uno

\footnotetext{
62 Ibídem, p. 157.

63 "El alférez...me parece una persona muy simpática"; "Los oficiales son las únicas personas simpáticas, y en parte son realmente muy finas"; "Mi comandante es muy amable conmigo"; "El capitán es un hombre de una infinita simpatía (también todos los demás [oficiales] fueron de una amabilidad enorme"; suben unos oficiales a bordo del Goplana y anota, "Entablé conversación con uno de ellos...Hablamos muy a gusto durante más de una hora. Fue muy afectuoso y nada tonto. Me propuso tutearnos, cosa que me alegró", Ibídem, pp. 43, 109, 153 у 75.

64 Ibídem, p. 165.

65 Ibídem, p. 43.

${ }^{66}$ Loc. cit.
} 
mismo y cuánta para los demás? ¡Es difícil llevar una vida buena! Pero la vida buena es bella “¡Pero no se haga mi voluntad sino la tuya!”.67

Como es patente, esa voluntad divina que Wittgenstein invoca, y a la cual apela, no es asimilable a aquella invocada por Tolstoi, que mandaba que "el hombre debe consagrar su vida al servicio de los hombres".68 Para ser más precisos, en el texto recién citado se expresa no tanto una ambigüedad cuanto una ambivalencia que parece incluso caer en el cálculo. Por un lado la forma más fácil de perderse es darse a los demás, se debe dejar que los otros se basten así mismos porque no habrá reciprocidad o será precaria. Además, si ya es necesario un espíritu fuerte para lidiar con uno mismo, es escéptico respecto de que tenga la suficiente fortaleza espiritual para entregarse a los demás. Pero por otra parte, intercalado con todo ello, se dice "Ayúdate a ti mismo y ayuda a los demás con toda tu fuerza". De nuevo es una cuestión de acento, pero significativo, pues esa ambivalencia, ese cálculo escéptico respecto de la reciprocidad de los otros y de la propia fortaleza de espíritu está lejos de aquella alegría de Vasili Brejunov cuando recibe la revelación del sentido de la vida ante Nikita moribundo. Alegría basada, recordémoslo, en que "tuvo la impresión de que él era Nikita y de que Nikita era él, y de que su vida no estaba en sí mismo, sino en Nikita".69 Dicho brevemente: la alegría de Tolstoi y la de Wittgenstein, ambas expresión de la vida con sentido, ambas de carácter religioso, tiene bases diferentes. La de Wittgenstein, hacer las cosas bien, cumplir el deber por el deber sin cálculo utilitario, conseguir indiferencia ante las contingencias del mundo y la subsiguiente paz de espíritu para poder trabajar en lógica (lo que, por cierto, es a su vez también una contribución a la vida del espíritu en lo que este tiene de transpersonal, es decir, cultural). Todo lo cual estaba anunciado cuando Wittgenstein declaraba que para salir airoso en cada instante de una vida que puede cesar en cualquier momento había que vivir en lo bueno y en lo bello hasta que la vida acabe. Peo hay que subrayar que, para él, el modo de consideración estético y ético radica en ver un objeto o el mundo (respectivamente) sub especie aeternitatis, es decir, consiste en una visión desde el exterior, no estando entre ellos. 70

Con todo, no es menos cierto que la ambivalencia de Wittgenstein en este punto comporta un malestar "abrasador" que le instiga a la comprensión y al reconocimiento de aquellos que considera incluso carentes de un "rastro de humanidad". Empecemos por el fuego que le abrasa. El 7 de marzo de de 1915 anota:

\footnotetext{
67 Ibídem, 30 de marzo de 1916, p. 143.

68 Tolstoi, L.: Religion et morale, op.cit. p. 40.

69 Tolstoi, L.: Amo y criado, en Relatos, op. cit. p. 392. Mío el énfasis.

70 Cf. Wittgenstein, L.: Cuadernos de notas 1914-1916, Madrid, Síntesis, 2009. 7 del 10 de 1916, p. 227.
} 
Están devorándome unas circunstancias repugnantes. Toda la vida exterior con toda su vulgaridad, se abalanza sobre mí. E interiormente estoy lleno de odio y no consigo dejar que entre en mí el espíritu. Dios es amor Soy como un hornillo consumido, lleno de escoria y suciedad 71

Otras veces afirma que ocurre "contra su voluntad" que las personas que le rodean le den "asco", pero, dice, "No las odio".72

Bien, ¿Cómo se conjuga todo ello con ese Dios que es amor? En El Evangelio Abreviado de Tolstoi que Wittgenstein leyó, la enseñanza de Jesús, despojada de su ropaje supersticioso (es decir, que se encarnara en la virgen María por obra del Espíritu Santo, el sistema de premios y castigos en la vida eterna, la resurrección a los tres días, los ángeles, los demonios, la creación del mundo en seis días, el paraíso, los primeros padres y su reptil tentador, etc), digo, la enseñanza de Jesús, se resume en una máxima, "amarás a Dios y al prójimo como a ti mismo", que se desglosa en cinco normas o mandamientos para enfrentarse y superar las correspondientes tentaciones: no encolerizarse, no cometer adulterio, no jurar, no resistir el mal con el mal y no tratar como enemigo a nadie. Con esos mandamientos, referidos al Sermón de la Montaña, acaba también su novela Resurrección, donde se dice que el cumplimiento de los mismos establecería una sociedad humana completamente nueva en la que desaparecería la violencia y se alcanzaría el mayor bien de la humanidad, el "Reino de Dios en la tierra".73

Pues bien, de ese Dios que es amor, así cifrado, Wittgenstein (descontado el adulterio) parece seguir tan sólo el mandamiento de no encolerizarse, en cuya aplicación hace esfuerzos denodados en su intento de comprensión y reconocimiento de los otros. Ahora bien, es notable que salvo en el segundo y el tercer mandamiento en la formulación tolstoiana de los tres restantes juegan un papel central nociones como no "irritarse", no "enojarse", "perdonar", no "odiar", "soportar con resignación"..... Y todas estas nociones son las que encontramos en aquellas anotaciones de Wittgenstein donde, como digo, intenta el reconocimiento y la reconciliación con

\footnotetext{
71 Wittgenstein, L. Diarios Secretos, op. cit. p. 131.

72 Ibídem, 28 de mayo de 1916, p. 151-152.

73 Cf. Tolstoi, L.: Resurrección, op. cit, p. 616; "El primer mandamiento (San Mateo, cap. V, 21-26) consistía en que el hombre no debe matar, irritarse, ni despreciar a sus hermanos; si se enojare ha de reconciliarse con su adversario antes de ofrecer un sacrificio a Dios, es decir, rezar. El segundo mandamiento (San Mateo, Cap. V, 27-32) decía que el hombre no debe cometer adulterios ni codiciar a una mujer por su belleza, y una vez casado ha de permanecer fiel. El tercer mandamiento (San Mateo, cap. V, 33-37), que el hombre no debe prometer nada por medio del juramento. El cuarto mandamiento (San Mateo, cap. V, 38-42), que el hombre no debe pagar ojo por ojo, sino ofrecer la otra mejilla cuando le hieren la diestra, debe perdonar las ofensas, soportarlos con resignación y no negar nada de lo que le pidan los semejantes. El quinto mandamiento (San Mateo, cap. V, 43-48), que el hombre no debe odiar a sus enemigos ni luchar contra ellos, sino amarles, ayudarles y servirles" Ibídem, pp. 616617.
} 
los otros a pesar de su tendencia que he llamado, para abreviar, aristocratismo del espíritu:

¡Comprende a las personas! ¡Siempre que vayas a odiarlas, trata de comprenderlas. ¡Vive en paz interior! 74

No es que la gente sea tonta, sino de cortos alcances. En su propio círculo son bastante listas. Pero les falta carácter y, con ello, la amplitud de miras. "El corazón creyente comprende todo". 75

No te irrites con las personas. Las personas son unos grises sinvergüenzas. Y, sin embargo, no tienes derecho a irritarte con ellas. Sus palabras no deben penetrar en ti. Si ellas no te hablan, aún es más fácil conservar la calma. Pero cuando se vuelven insolentes y groseras contigo, entonces todo hierve en ti. No te irrites. De nada sirve enfadarse. ${ }^{76}$

Después de la última anotación que cierra los Diarios Secretos, tras las batallas que se libraron cerca de Okna, haber sido ascendido a sargento y condecorado con la Medalla al Valor, Wittgenstein se trasladó a la Escuela de Oficiales de Olmütz, en Moravia, donde se encontró por primera con el que sería su amigo, el arquitecto Paul Engelmann. Del escrito de memoria que Engelmann dejó sobre Wittgenstein, llama la atención que el apartado dedicado a la religión empiece por reflexiones sobre la guerra. Por entonces, cuando los frentes se habían estabilizado desde 1915 y todos vieron que la guerra no sería un paseo caballeresco que debería haber acabado en las Navidades de 1914, Engelmann ya había abandonado el general arrebato belicista de agosto de 1914, colaborando incluso con un pacifista de primera hora, Karl Kraus. 77

Si traigo este asunto es porque en la oposición entre Engelamnn y Wittgenstein se muestra bien hasta qué punto el autor del Tractatus era distante de Tolstoi en el entendimiento de la voluntad divina en cuya entrega ambos cifraban el sentido de la vida.

Decir que Engelmann era pacifista no es decir mucho todavía, porque en la guerra del catorce surgieron muy distintos tipos de pacifismo. No puedo abordar aquí la cuestión, pero sirva decir que no significaba lo mismo "ser pacifista" para Russell, Barbusse, Remarque, Zweig, Sassoon, Ernst Freidrich, Lenin, etc.78.

\footnotetext{
74 Wittgenstein, L. Diarios Secretos, op. cit., 6 de mayo de 1916, p. 149.

75 Ibídem, 8 de mayo de 1916, p. 149.

76 Ibídem, p. 153, 9 de julio de 1916.

77 Le ayudaba recortando periódicos a escribir una de las obras que quizá sea la que formalmente mejor exprese el derrumbe del orden europeo anterior al atentado de Sarajevo, Los últimos días de la humanidad.

78 Cf. Sánchez Durá, N. "Rojo sangre, gris de máquina. E. Jünger y la inscripción técnica de un mundo peligroso", en Jünger, E. El Mundo Transformado seguido de El Instante Peligroso. Valencia, Pretextos, 2005.
} 
Además, debe subrayarse que una cosa fue el pacifismo que se expresó en la guerra y otra bien distinta el que se elaboró en el periodo de entreguerras, que resignificó textos e imágenes que en su día habían tenido un sentido beligerante.

Cuando se encontró con Wittgenstein, Engelmann opinaba que su oposición a la guerra no le eximía del servicio militar. Argumentaba que sólo estaba justificado en romper una obligación como la patriótica en nombre de una más alta sí y sólo sí se comprometía con una acción igualmente seria en favor de esa obligación superior, entendiendo por tal una acción "igual de peligrosa personalmente". Por tanto no participaba ni de la opinión de que "por su ánimo personal pacifista se anulara la obligación general frente al Estado", ni de la opinión de uno de los tipos de pacifismo existente, a saber, que la vida humana "es el mayor de los bienes posibles en cualquier circunstancia"; él "sólo sentía que hay bienes más altos, pero que está prohibido aniquilar la vida por algo menos valioso que los bienes supremos". Engelmann afirma que Wittgenstein tenía "una opinión completamente diferente...Consideraba su obligación ir a la guerra como algo que había que cumplir en cualquier circunstancia". Además, añade, entre el punto de vista de ambos no podía haber "compromiso alguno". 79

Cuando Wittgenstein leyó El Evangelio Abreviado y los Relatos de Tolstoi el escritor ruso era enormemente famoso tanto por su literatura como por sus ensayos y su pacifismo militante totalmente opuesto por principio a la guerra. En cualquier caso, la conclusión de su crítica de los evangelios, repetida de todas las maneras posibles en sus Relatos, por cuanto sacralizaba los vínculos fraternos entre la humanidad, proscribía radicalmente la agresión violenta y la muerte, incluso considerar a un semejante como enemigo. Entre otros hoy menos conocidos, todo su ensayo $E l$ reino de Dios está en vosotros (1890-1893) se dedica a desarrollar este aspecto. Es obvio que en este aspecto Wittgenstein estaba muy lejos de Tolstoi y su entendimiento de la voluntad divina.

Creo que la percepción de Engelmann sobre el tipo de religiosidad de Wittgenstein en estos años es muy perspicaz. No lo define como un agnóstico, si por ello se entiende alguien cuyo interés es polemizar para que su interlocutor adopte una posición escéptica respecto de la pertinencia del punto de vista religioso. Ciertamente compartía con Tolstoi su aversión por la pompa eclesial, la hipocresía religiosa bienpensante y la idea de un Dios creador o dispensador de premios y castigos en una vida común de los muertos más allá de ésta. Creía que la infelicidad radicaba en un desequilibrio entre él y la vida tal como es, pero a la vez pensaba que debía reconocer que la culpa de ese desequilibrio no la tenía la vida sino cómo era él, sin achacar su modo de ser a las circunstancias exteriores. Desde luego cabe otra opción: pensar que puede alterarse los datos del problema y dedicarse a cambiar las

79 Engelmann, en P. Wittgenstein-Engelman, Cartas, Encuentros, Recuerdos, op. cit. p. 125. 
circunstancias de la vida como forma de colmar aquel desequilibrio que me hace infeliz. Y, de hecho, el punto de vista religioso de Tolstoi y la moral pública que implica permiten, incluso instigan, tal actitud de intervención en el mundo. Por ello Tolstoi fue un hombre que no se inhibió políticamente y Wittgenstein sí, pues pensaba que el ámbito privilegiado de la intervención era el dominio de sí. Precisamente para él, en su juventud, lo religioso era el reconocimiento de ese desequilibrio, manteniéndolo siempre a la vista como acicate de autoexigencia moral y descartando considerar que los hechos que circunscribían su vida debieran ser alterados porque justamente en esa realidad dada era dónde debía demostrar que su espíritu (en un sentido) daba la medida del Espíritu (en otro sentido).

Engelmann aporta dos testimonios en extremo interesantes para reafirmar lo dicho. El primer testimonio refiere a la idea de Juicio Final; el segundo, al comentario que ambos hicieron del relato de Tolstoi Los dos ancianos (1885). Respecto del Juicio Final es llamativo que a alguien que no creía en una vida después de la muerte le obsesionara tal idea hasta el punto de que en los momentos más serios de una conversación repetidamente exclamara: "Cuando nos veamos un día en el Juicio Final". Según Engelmann la profería con "una mirada indescriptible, vuelta hacia dentro, con la cabeza baja, dando toda la imagen de un poseso". 80 En efecto, vuelto hacia adentro y poseso de sí, porque aquí juicio final creo que quiere decir: el juicio total e inclemente que algún día inapelablemente yo Wittgenstein concluya sobre mí. En esa ansiedad de absolución interior personal, de salvación despreocupada del próximo, no está Tolstoi.

El segundo testimonio versa sobre el relato Los dos ancianos y transita en la misma dirección. Pues es sorprendente -o no tanto, según lo dicho- el punto en el que Wittgenstein se fijó en su comentario. En cualquier caso, para Tolstoi la enseñanza principal de ese relato, que comparte la estructura de parábola con muchos otros, no es la que extrajo Wittgenstein. Dos campesinos pobres, uno con algún bien material más que el otro, deciden cumplir la promesa de peregrinar a Jerusalén. Ambos hacen un gran esfuerzo económico por reunir el dinero necesario. El de mayores recursos anda preocupado por qué pasará en su ausencia; el otro, Yeliséi, confía en su hijo y su mujer. Al llegar a Ucrania, en una zona de gran hambruna por causa de la mala cosecha, Yeliséi se detiene en una isba para coger agua con la intención de alcanzar a su compañero Yeftin más tarde. Pero la situación que encuentra es desoladora: un hombre, su mujer, una niña y una anciana yacen a punto de morir absolutamente depauperados por el hambre. Decide quedarse para ayudarles. En este punto es significativa la secuencia de los acontecimientos que Tolstoi escribe: lo que empieza siendo una simple limosna de la comida que Yeliséi lleva consigo, se convierte en una estancia más larga donde fabrica con sus manos las

80 Ibídem, p. 130. 
cosas necesarias o gasta todo su dinero comprándolas. Porque asistir a esa gente más allá de la piedad inmediata, que sanen y recuperen los medios para que puedan mantenerse y aprovechar la cosecha futura, supone deshipotecar las tierras, comprar una carreta y un caballo, etc. Mientras, su compañero de promesa, Yeftin, llega a los Santos Lugares, descritos como un carrusel de supersticiones cuyo fin es que los peregrinos gasten lo que tienen en beneficio de quienes los administran. Entre empujones y desánimo, por dos veces cree Yeftin ver a Yelisei como una aparición santa en un altar. Pero en su camino de vuelta Yeftin encuentra a los que Yeliséi asistió. Le cuentan de él como de un santo ejemplar: "Si no hubiera venido, habríamos muerto todos en el pecado...porque moríamos en la desesperación, maldiciendo a Dios y a los hombres. Él nos sacó de apuros, nos enseñó a conocer a Dios y a tener confianza en los hombres de bien...Antes vivíamos como las bestias, él nos convirtió en seres humanos". ${ }^{81}$ Cuando llega a su pueblo Yeftin encuentra su hacienda decaída y su hijo le ofende; él le pega. Quiere ver a Yeliséi que, para explicar su pronto regreso, ha preferido pasar por un simple en el poblado diciendo que fue robado. Lo encuentra con sus abejas:

...vio a su amigo debajo de un abedul...tenía los brazos extendidos y miraba hacía lo alto, su calva relucía como en Jerusalén, cuando estaba junto al Santo Sepulcro; los rayos de sol se filtraban a través de las ramas de abedul y brillaban como lenguas de fuego igual que las lamparillas en los Santos lugares, y las doradas abejas revoloteaban alrededor de su cabeza formando una especie de corona, lo rozaban y no le picaban. 82

Yeftin, concluye que si sus pies estuvieron en Jerusalén no lo estuvo su alma. Al contrario que su amigo Yeliséi, que se quedó en el camino en aquella isba. Sin embargo, éste no quiere hacer ningún comentario “¡Todo está en manos de Dios!”, repite ofreciéndole su miel. Yeftin comprende, dice Tolstoi, "que el mejor modo de cumplir los votos hechos a Dios es amar y hacer el bien a los semejantes hasta la muerte." 83

Cuenta Engelmann que Wittgenstein se fijo en un pequeño pasaje que no he citado. Antes de encontrar la isba desolada por el hambre y la muerte, los dos amigos se paran a descansar. Yeliséi que bebía vodka, fumaba y esnifaba rape, saca su tabaquera. Yeftin le recrimina que ese vicio no es propio de un peregrino, y Yeliséi le replica: "iQué le vamos a hacer! El vicio es más fuerte que yo!"84

Pues bien, eso fue lo que despertó el comentario de Wittgenstein. En ese reconocimiento de Yeliséi veía un signo del auténtico estado anímico religioso: “"nin-

\footnotetext{
81 Tolstoi, L.: Los dos ancianos, en Relatos, op. cit, p. 339.

82 Ibídem, p. 340.

83 Loc. cit.

84 Ibídem, pág. 322. En la versión española de Engelmann, Yeliséi no dice "vicio", sino "tentación".
} 
guna disculpa ante sí mismo y ante los otros', pues no se trataba propiamente de ningún pecado, sino de que se es inferior a él". ${ }^{85}$ No creo que se pueda mostrar más claramente las diferencias entre la religiosidad del Tolstoi maduro y la del joven Wittgenstein, por más que ambos digan entregar su alma a Dios para que se cumpla su voluntad.

Tolstoi fue una influencia duradera y un interlocutor constante a lo largo de la vida de Wittgenstein. Pero la forma en que pensó a partir de la obra del escritor ruso varió a lo largo de los años. Algunas intuiciones filosóficas alcanzadas tras su lectura, sufrieron continuos cambios, a veces imperceptibles, que le llevaron a pensar la religión de forma diferente a la del periodo de su juventud. Pues si bien en sus primeros años encontramos un joven creyente de características muy peculiares basadas en sus experiencias existenciales, más tarde encontramos alguien empeñado en describir la lógica -o la gramática profunda- de toda creencia religiosa, incluidas las de su juventud. Pero esa ya es otra historia de la que no hablaré aquí.

Nicolás Sánchez Durá

Departamento de Metafísica y Teoría del Conocimiento

Universidad de Valencia

nicolas.sanchez@uv.es

85 Engelmann, P. en Wittgenstein-Engelmann, Cartas, Encuentros, Recuerdos, op. cit. p. 132. 